\title{
Saccadic latency in hepatic encephalopathy: a pilot study
}

\author{
Florian Krismer • Jonathan C. P. Roos • Melanie Schranz • Ivo W. Graziadei • \\ Sergei Mechtcheriakov • Wolfgang Vogel $\cdot$ R. H. S. Carpenter $\cdot$ Heinz Zoller
}

Received: 8 February 2010 / Accepted: 13 May 2010 /Published online: 18 September 2010

(C) 2010 The Author(s). This article is published with open access at Springerlink.com

\begin{abstract}
Hepatic encephalopathy is a common complication of cirrhosis. The degree of neuro-psychiatric impairment is highly variable and its clinical staging subjective. We investigated whether eye movement response timessaccadic latencies - could serve as an indicator of encephalopathy. We studied the association between saccadic latency, liver function and paper- and pencil tests in 70 patients with cirrhosis and 31 patients after liver transplantation. The tests included the porto-systemic encephalopathy (PSE-) test, critical flicker frequency, MELD score and ammonia concentration. A normal range for saccades was established in 31 control subjects. Clinical and biochemical parameters of liver, blood, and kidney function were also
\end{abstract}

Florian Krismer and Jonathan C. P. Roos contributed equally to this work.

Electronic supplementary material The online version of this article (doi:10.1007/s11011-010-9210-1) contains supplementary material, which is available to authorized users.

F. Krismer · M. Schranz · I. W. Graziadei $\cdot$ W. Vogel ·

H. Zoller $(\bowtie)$

Department of Medicine II-Gastroenterology and Hepatology,

Medical University of Innsbruck,

Anichstrasse 35,

A-6020 Innsbruck, Austria

e-mail: heinz.zoller@i-med.ac.at

J. C. P. Roos

Department of Medicine, University of Cambridge,

Cambridge CB2 2QQ, UK

R. H. S. Carpenter

Department of Physiology, Development and Neuroscience,

University of Cambridge,

Cambridge CB2 3EG, UK

S. Mechtcheriakov

Department of Psychiatry, Medical University of Innsbruck,

Innsbruck, Austria determined. Median saccadic latencies were significantly longer in patients with liver cirrhosis when compared to patients after liver transplantation (244 ms vs. $278 \mathrm{~ms} p<$ $0.001)$. Both patient groups had prolonged saccadic latency when compared to an age matched control group (175 ms). The reciprocal of median saccadic latency $(\mu)$ correlated with PSE tests, MELD score and critical flicker frequency. A significant correlation between the saccadic latency parameter early slope $\left(\sigma_{\mathrm{E}}\right)$ that represents the prevalence of early saccades and partial pressure of ammonia was also noted. Psychometric test performance, but not saccadic latency, correlated with blood urea and sodium concentrations. Saccadic latency represents an objective and quantitative parameter of hepatic encephalopathy. Unlike psychometric test performance, these ocular responses were unaffected by renal function and can be obtained clinically within a matter of minutes by non-trained personnel.

Keywords Liver cirrhosis - Liver transplantation . Eye movements $\cdot$ Brain function - Ammonia

\section{Introduction}

Hepatic encephalopathy (HE) is a common complication of liver cirrhosis. The diagnosis is made in the presence of acute or chronic liver disease, with or without portosystemic shunting, after other causes of encephalopathy, such as intracranial haemorrhage, stroke, intoxication, severe electrolyte imbalances, acid-base disorders, acute infection and hypoxia have been excluded (Ferenci et al. 2002). Although encephalopathy is associated with EEG abnormalities and changes on magnetic resonance imaging, none of these is specific or can be readily used for follow up to assess disease progression (Rovira et al. 2002). 
Clinical presentation is highly variable and ranges from minimal impairment of cognitive function to coma. Thirty per cent of patients with liver cirrhosis have obvious psychomotor impairment but sub-clinical changes in cognitive function are present in most patients (Jalan and Hayes 1997). This variability makes grading individual patients and assessing their response to treatment more difficult. Despite the advantages of clinical grading using the West-Haven criteria, this method is subjective and therefore of limited use both clinically and for research (Mechtcheriakov et al. 2005).

Accurate grading of HE remains challenging. The plasma concentration of ammonia correlates poorly with degree of HE (Kramer et al. 2000) even if it is determined in arterial blood and its partial pressure calculated from the $\mathrm{pH}$ (Kramer et al. 2000; Manning 1964). Ammonia is believed to be central to the pathogenesis of HE associated with acute liver failure (Butterworth 2002; Butterworth et al. 1987; Kramer 2004).

Psychometric tests are an alterbnative method for assessing and grading HE (Kircheis et al. 2002). The porto-systemic encephalopathy (PSE) test comprises of a test panel, in which pattern recognition, memory, attention span and motor impairment are assessed. Although this is objective and reproducible, its application in clinical practice is limited by the time requirements and need for a trained assessor (Kircheis et al. 2007).

Another sensitive and quantitative tool for grading encephalopathy is critical flicker frequency (CFF), determined using the Hepatonorm Analyzer ${ }^{\mathrm{TM}}$, an instrument designed for bed-side use (Kircheis et al. 2002). CFF is thought to be principally dependent on retinal function which is believed to mirror the cerebral changes seen in HE (Kircheis et al. 2002). The test has mainly proved useful for quantifying mild to moderate impairment as it requires patient compliance.

Somooth pursuit eye movements have been more recently shown to correlate with the degree of neurologic impariment, but their use is limited by the need for specialized equipment and head fixation (Montagnese et al. 2005).

To evaluate the feasibilty of saccadometry for the diagnosis and grading of HE, saccadic latencies which typically range between $150 \mathrm{~ms}$ and $220 \mathrm{~ms}$ in normal subjects (Reddi and Carpenter 2000) were assessed in patients with liver cirrhosis and after liver transplantation. Saccadic latencies represent the time taken for patients to respond to a visual target by generating an eye movement to fixate on it. This requires cortical processing and prolonged saccadic latencies have been found in cerebral impairment in schizophrenia (Karoumi et al. 1998) and neurodegenerative diseases (Parkinson's and Huntingdon's disease)(Ali et al. 2006; Foltynie et al. 2004; Michell et al.
2006) as well as lysosomal storage diseases (Roos et al. 2006).

Latencies are highly variable and this randomness has tended to limit their use for staging and diagnosis of neurological diseases (Ali et al. 2006; Antoniades et al. 2007; Carpenter et al. 2002; Khan et al. 1999; Michell et al. 2006; Nouraei et al. 2003; Pearson et al. 2007). However despite their randomness, saccadic latencies follow a characteristic skewed distribution that can be transformed to a Gaussian distribution by plotting their cumulative frequency against the reciprocal of latency (Figs. 1 and 2). Consequently, if this frequency is plotted on a probit scale, the majority of saccadic latencies lie on a straight line (Fig. 3) (Carpenter and Williams 1995). In this manner, a complex dataset of usually 200-500 individual saccadic latencies from a single patient can be described by just three parameters. These parameters are $(\mu)$, the mean of the reciprocal of saccadic latency, $(\sigma)$, its standard deviation, and $\left(\sigma_{\mathrm{E}}\right)$, the standard deviation of the sub-popuation of early saccades, that escape normal tonic inhibition from the cortex (typically $<5 \%$ of saccades). This forms the basis of the LATER model (linear approach to threshold with ergodic rate) of decision making which essentially describes how pre-test likelihood and urgency affect decision time and threshold in neuronal circuits (Reddi and Carpenter 2000). (see www.cudos.ac.uk/later.html for further details).

The severity of HE typically correlates with degree of liver function impairment and transplantation is associated with major improvement of encephalopathy in a majority of patients (Moore et al. 2000), although residual neuropsychiatric impairment has been reported long-term postoperatively (Mechtcheriakov et al. 2004). We sought to determine the value of saccadometry for diagnosis and grading of $\mathrm{HE}$ and studied saccadic latencies in patients with liver cirrhosis before and after transplantation as well as in controls and found that saccadic latencies were significantly shorter in controls than in transplanted patients and in patients with liver cirrhosis, where differences between transplanted and cirrhotic patients were also highly significant. Results were correlated with those from established tests for liver and brain function as well as inflammatory, metabolic and renal blood tests. This correlation analysis showed the practical value of saccadometry which correlates well with the psychometric test score and MELD score.

\section{Patients and methods}

This study was approved by the Research Ethics Committee of Innsbruck Medical University (UN3231) where this study was conducted. Informed consent was obtained from 
Fig. 1 Box-Whisker blots for individual surrogate markers of hepatic encephalopathy. The median is indicated by a horizontal line. Boxes indicate the 25th and 75 th percentile and whiskers the range. Outliers are marked by circles. For saccadic latency the median of 200 individual saccadic latency times in each patient was calculated and for critical flicker frequency the median of 6 individual measurements in each patient was calculated. (Note that the differences in numbers are due to difficulties in obtaining PSE test results, $\mathrm{CFF}$ and $\mathrm{pNH}_{3}$ in some patiens)


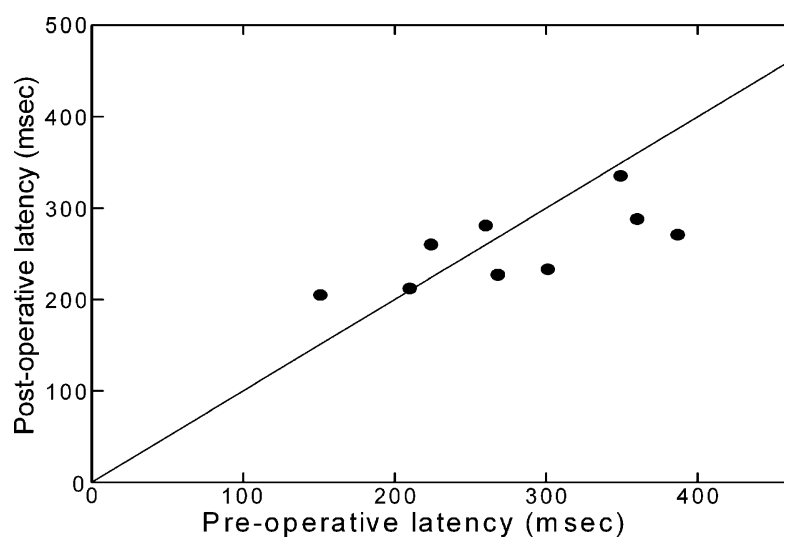

Fig. 2 Paired measurements of median saccadic latency before and after transplant in nine patients: the line represents the expected relationship if there is no change. Five patients showed significant reduction in latency, three patients showed a significant increase. (Changes in median saccadic latency were tested for significance in each patient by student's $t$-test of $\log$ transformed data. Two hundred individual saccadic latency times were recorded for each patient before and 200 after transplantation). Note that a decrease in latency tends to occur in patients whose latencies were longer before the operation, i.e. those whose saccades were more severely affected by cirrhosis all patients before study enrolment. Seventy cirrhotic patients were recruited to the study, nine of whom underwent liver transplantation during the study period and could be reassessed afterwards. We also recruited an additional 22 patients who had previously undergone liver transplantation, enabling us to study 31 transplanted patients. As a control, saccadic latencies were also determined in 31 healthy volunteers matched for age and sex. Demographic data, cause of liver disease, renal and liver function are presented in Table 1. No statistically significant differences for age or gender were noted between the pre- and post-transplant patient groups. Amongst the cirrhotic patients, fatty liver disease was the most common cause of cirrhosis $(59.7 \%)$ and also the most common indication for liver transplantation (30.3\%). UNOS modified MELD scores were calculated on the basis of the INR, bilirubin and creatinine concentrations but excluding the extra score-points for hepatocellular carcinoma. All investigations took place between 9 and $12 \mathrm{am}$. As benzodiazepines influence saccadic latency (de Visser et al. 2003), patients who had received these drugs within $72 \mathrm{~h}$ prior to assessment were excluded. Other clinical biochemical parameters were determined on the same day using routine methods including urea, creatinine, sodium, potas- 
Fig. 3 Scatter blots of surrogate markers of hepatic encephalopathy. Results from correlation tests are shown in Table 4. Individual results are depicted by circles. Regression lines and $95 \%$ confidence intervals for linear regression are shown
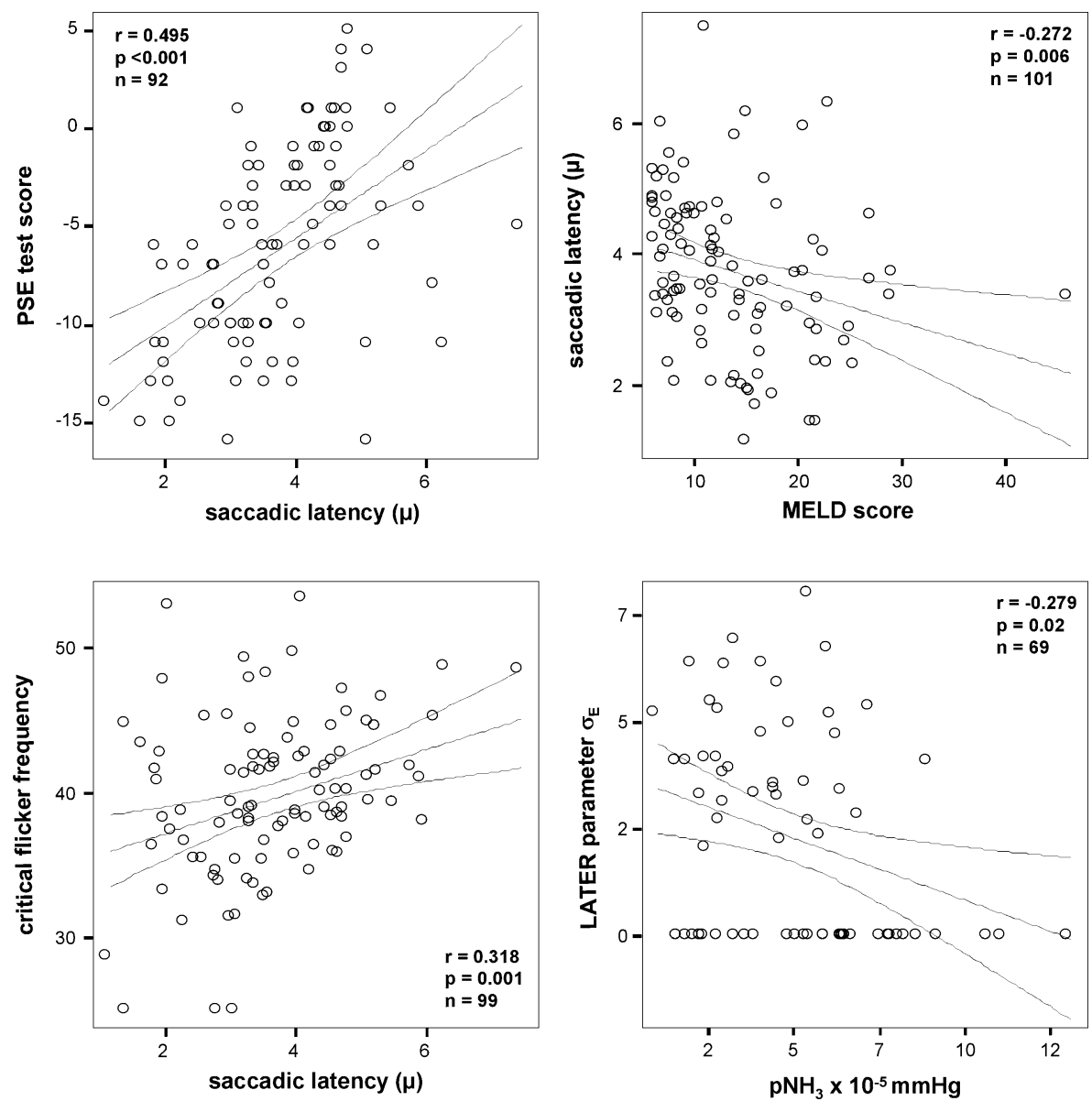

sium, chloride, transaminases (ALT, AST and $\gamma$-GT), blood count, haemoglobin concentration, prothrombin time, C-reactive protein, albumin and bilirubin. Partial pressure of ammonia was calculated in 69 patients using arterial blood (Kramer et al. 2000), according to the method of Manning (Manning 1964).
Psychometric test

Patients underwent standard investigations for HE. PaperPencil Tests were carried out with all patients, including the number connection tests $\mathrm{A}$ and $\mathrm{B}$, the digit-symbol test, the serial dotting test and line tracing (Ferenci et al. 2002;

Table 1 Characteristics of patients enrolled in this study

\begin{tabular}{llll}
\hline & & Patients with liver cirrhosis $(n=70)$ & Patients after liver transplantation $\left(n=31^{\mathrm{a}}\right)$ \\
\hline Sex & male & $45(64.3 \%)$ & $24(75 \%)$ \\
& female & $25(35.7 \%)$ & $8(25 \%)$ \\
Age & mean $( \pm \mathrm{SD})$ & $54.4( \pm 11.4)$ & $56.8( \pm 10.4)$ \\
Disease & fatty liver disease & $43(59.7 \%)$ & $9(28.1 \%)$ \\
& hepatitis C cirrhosis & $12(17.1 \%)$ & $6(18.8 \%)$ \\
& others & $15(21.4 \%)$ & $17(53.1 \%)$ \\
UNOS modified MELD score: & mean $(95 \% \mathrm{CI})$ & $15.1(14.1-17.5)$ & $\mathrm{n} / \mathrm{a}$ \\
Creatinine & mean $(95 \% \mathrm{CI})$ & $1.1(0.9-1.3)$ & $1.1(1.0-1.2)$ \\
Bilirubin & mean $(95 \% \mathrm{CI})$ & $5.8(3.2-8.5)$ & $2.4(0.7-4.2)$ \\
INR & mean $(95 \% \mathrm{CI})$ & $1.5(1.3-1.7)$ & $1.1(1.0-1.1)$
\end{tabular}

${ }^{\text {a }}$ Nine patients who were analyzed before and after liver transplantation were counted twice in both groups. Other causes of cirrhosis included autoimmune hepatitis, hepatitis B, cholestatic and metabolic liver diseases 
Schomerus and Hamster 1998; Schomerus et al. 1999; Weissenborn et al. 2001). We applied the PSE syndrome test of Swets Test Services (Frankfurt, Germany) which was standardized for age in healthy German volunteers. Normal results range from -4 to +6 points. A score of -5 points or less is considered pathologic. Four different forms of the test are available for follow-up investigations.

\section{Critical flicker frequency}

CFFwas determined using the HepatoNorm ${ }^{\mathrm{TM}}$ Analyzer (Kolassa Merz Vienna, Austria) consisting of a head mounted projection unit and a hand held micro-controller. For this test, the patient is instructed to concentrate on a red spot which flickers with a frequency of $60 \mathrm{~Hz}$. The frequency is then decreased with a variable rate of 0.1 to $1.0 \mathrm{~Hz}$ per second to a final frequency of $25 \mathrm{~Hz}$. Healthy volunteers are able to recognize flickering at $\sim 42 \mathrm{~Hz}$ (Kircheis et al. 2002), whereas patients with hepatic encephalopathy have a reduced 'critical flicker frequency' with a threshold of 38-39 Hz (Romero-Gomez et al. 2007). After a training measurement, six single measurements were carried out and the median of the 6 readings was calculated.

\section{Saccadic latencies}

Saccadic latency was measured using a $1 \mathrm{kHz}$, head-mounted, non-invasive infra-red scleral reflection oculometer (Ober consulting, Poland) (Ober et al. 2003), whose output was low-pass filtered at $250 \mathrm{~Hz}$ with 12-bit resolution. A differential amplifier eliminated any convergence and vergence movements. Three laser diodes projecting red visual targets with an intensity of $13 \mathrm{cdm}^{-2}$ were mounted on top of the device, ensuring that they were presented in a fixed position (one in the midline, the others at $10^{\circ}$ to right and left) relative to the head. This obviates the need for head immobilization which has been a necessary feature of most other oculometers (Cairney et al. 2005). Patients were instructed to 'look at the red dot', and performed a standard saccadic step task in which a central target was presented for a random fore-period in the range 0.5-1 s, and after its extinction a second target was presented randomly either to the left or the right and remained illuminated until $25 \mathrm{~ms}$ after the end of the saccade or for $1 \mathrm{~s}$, whichever was shorter. The target would thus appear to jump randomly $10^{\circ}$ horizontally to the right or left. This was repeated to generate 200 trials, typically taking about 5-8 $\min$ with $50 \%$ occurring to the right and $50 \%$ to the left on average; data were stored in the portable saccadometer and then downloaded onto a personal computer running Latency Meter 2.3 (Nouraei et al. 2003) which automatically purged erroneous data such as artefacts caused by blinks, head movements and saccades in the wrong direction. Saccadic latencies less than $50 \mathrm{~ms}$ were also ignored as these would be too fast to have been evoked by the visual stimuli.

Saccadic latency distributions were analyzed using the application SPIC (Carpenter 1994) which calculates best-fit LATER parameters $\left(\mu, \sigma\right.$ and $\left.\sigma_{\mathrm{E}}\right)$ by minimization of the Kolmogorov-Smirnov one sample (KS-1) statistic (Kolmogorov 1941) using $10 \mathrm{~ms}$ bins. These parameters are $(\mu)$, the mean of the reciprocal of saccadic latency, $(\sigma)$, its standard deviation, and $\left(\sigma_{\mathrm{E}}\right)$, the standard deviation of the sub-popuation of early saccades, if any. For statistical comparisons $\mu$, the reciprocal value of the saccadic latency (its units are $\mathrm{sec}^{-1}$ or Hertz) is preferred for statistical analysis over the median saccadic latency because of its normal distribution.

LATER is discussed in detail elsewhere (Carpenter and Williams 1995; Reddi et al. 2003; Temel et al. 2009) (see Supplementary Figure).

\section{Statistical analysis}

Study data of patients enrolled in this study were analyzed in SPSS version 15.0. Patients were divided into controls $(n=31)$ a group of cirrhotic patients $(n=70)$ and a group of patients who had undergone liver transplantation $(n=31)$. Normality of distribution was tested by Kolmogorov-Smirnov curve fitting analysis. If the distribution was normal, ANOVA or $t$-test for independent samples was carried out between the two groups. For the non-normally distributed data, the Mann-Whitney- $U$ test was used. Paired analysis of the data from the nine patients who were examined both before and after liver transplantation, was performed using the paired $t$-test and, for non-Gaussian data, the Wilcoxon test. Correlation analysis was carried out using the Pearson or Spearman rank test as appropriate.

\section{Results}

Hepatic encephalopathy before and after liver transplantation

Saccadic latency, psychometric test performance and CFF were assessed in patients with cirrhosis and in patients who had undergone liver transplantation. In addition, arterial partial pressure of ammonia was calculated for as many of these patients as technically possible. Table 2 shows statistically significant differences between these groups with better psychometric test performance ( -2 vs $-8 p<0.001)$, a shorter median saccadic latency in the transplanted group, i.e. a higher $\mu(4.1 \mathrm{vs} 3.6 \mathrm{~Hz} p=0.028)$ and a lower partial pressure of ammonia ( 2.6 vs $\left.5.9 \times 10^{-5} \mathrm{mmHg} p<0.001\right)$. The age and sex-matched control group had significantly shorter mean saccadic latency when compared with cirrhosis patients and patients after liver transplantation (Table 2, Fig. 1). Cluster 
Table 2 Surrogate markers for hepatic encephalopathy in patients with liver cirrhosis and those who have received liver transplants. Medians, 95\% confidence intervals and sample size [n] are shown.
Differences between groups were tested for statistical significance by Student's $t$-test or Mann-Whitney- $U$-Test for independent samples

\begin{tabular}{|c|c|c|c|c|c|}
\hline & & $\begin{array}{l}\text { Patients with liver } \\
\text { cirrhosis median } \\
(95 \% \text { CI })[n]\end{array}$ & $\begin{array}{l}\text { Patients after liver } \\
\text { transplantation median } \\
(95 \% \mathrm{CI})[n]\end{array}$ & $\begin{array}{l}\text { Control } \\
\text { subjects }[\mathrm{n}]\end{array}$ & Significance \\
\hline \multicolumn{2}{|l|}{$\mathrm{pNH}_{3} \times 10^{-5} \mathrm{mmHg}$} & $5.9(5.3-6.9)[48]$ & $2.6(2.2-3.2)[21]$ & n.a. & $<0.001$ \\
\hline \multicolumn{2}{|l|}{ PSE test } & $-8.0(-9.1--6.6)[59]$ & $-2.0(-4.1--1.2)[31]$ & n.a. & $<0.001$ \\
\hline & $38.8(37.9-40.6)[68]$ & $40.1(38.9-42.7)[31]$ & n.a. & 0.132 \\
\hline \multicolumn{2}{|l|}{$\begin{array}{l}\text { Median saccadic } \\
\text { latency }[\mathrm{ms}]\end{array}$} & $278(256-303)[70]$ & $244(222-263)[31]$ & $175(175-196)[31]$ & $\begin{array}{l}0.028^{\mathrm{a}} \\
<0.001^{\mathrm{b}} \\
<0.001^{\mathrm{c}}\end{array}$ \\
\hline \multirow[t]{3}{*}{ LATER parameters } & $\mu$ & $3.6(3.3-3.9)[70]$ & $4.1(3.8-4.5)[31]$ & $5.7(5.1-5.8)[31]$ & $\begin{array}{l}\mathbf{0 . 0 2 8}^{\mathrm{a}} \\
<0.001^{\mathrm{b}} \\
<0.001^{\mathrm{c}}\end{array}$ \\
\hline & $\sigma$ & $1.0(0.9-1.0)[70]$ & $1.1(0.9-1.2)[31]$ & $0.9(0.84-1.1)[31]$ & $\begin{array}{l}0.195^{\mathrm{a}} \\
0.738^{\mathrm{b}} \\
0.298^{\mathrm{b}}\end{array}$ \\
\hline & $\sigma_{\mathrm{E}}$ & $2.77(1.82-2.98)[70]$ & $3.64(2.22-3.88)[31]$ & $2.20(0.97-3.1)[31]$ & $\begin{array}{l}0.287^{\mathrm{a}} \\
0.292^{\mathrm{b}} \\
0.307^{\mathrm{c}}\end{array}$ \\
\hline \multicolumn{2}{|c|}{$\begin{array}{l}\text { ANOVA of all LATER parameters } \\
\text { (combined sum of squares) }\end{array}$} & $\begin{array}{l}\text { liver cirrhosis vs. after LT } \\
\boldsymbol{p}=\mathbf{0 . 0 1 8}\end{array}$ & $\begin{array}{l}\text { after LT vs. controls } \\
\boldsymbol{p}=\mathbf{0 . 0 0 5}\end{array}$ & $\begin{array}{l}\text { controls vs. liver cirrhosis } \\
\boldsymbol{p}<\mathbf{0 . 0 0 1}\end{array}$ & \\
\hline
\end{tabular}

Differences in LATER parameters between the three groups were analyzed by ANOVA (separate sum of squares; ${ }^{a}$ patients with liver cirrhosis vs. patients after liver transplantation, ${ }^{\mathrm{b}}$ patients with liver cirrhosis vs. controls, ${ }^{\mathrm{c}}$ patients after liver transplantation vs. controls)

analysis of all combined saccadic latency parameters (calculated from the LATER model) showed significant differences between the three groups (Table 2). The mean CFF was higher in patients after liver transplantation, but did not reach statistical significance.

Nine individual patients were assessed before and after transplantation at our centre. Paired analysis for the individuals showed improved psychometric test performance by a mean of 5 points $(p=0.014)$. Arterial partial pressure of ammonia $\left(\mathrm{pNH}_{3}\right)$ decreased by a mean of $3.96 \times$ $10^{-5} \mathrm{mmHg}$ after liver transplantation $(p=0.014)$ in this paired analysis. The mean reduction in saccadic latency after liver transplantion was $7.7 \mathrm{~ms}$, which did not reach statistical significane in this smaller subgroup of 9 patients (Table 3). However as individuals there was a significant improvement in 5 patients and no change in one patient. In the three patients who showed a prolongation of saccadic latencies after liver transplantation, these changes mirrored clinical derterioration. Paired measurements of median saccadic latency before and after transplant showed that a decrease in latency tends to occur in patients whose latencies were longer before the operation, i.e. those whose saccades were more severely affected by cirrhosis (Fig. 2).

Figure 4 and Table 4 show the data from a representative patient who was tested repeatedly whilst awaiting a donor liver. Clinically his encephalopathy worsened significantly whilst on the waiting list and improved markedly post- transplant - a result that is accurately mirrored by the changes in his median latencies and is highly statistically significant. We also analyzed the distribution of data from those of our patients who did not show improvement in their median reaction times post-transplant.

Correlation analysis of surrogate parameters for hepatic encephalopathy

Interdependence between surrogate parameters for grading of hepatic encephalopathy were assessed by correlation analysis. The significant relationship between median latency $(\mu)$, PSE Test score, CFF and MELD score is shown in Fig. 3. The LATER parameter $\sigma_{\mathrm{E}}$ correlated negatively with the partial pressure of ammonia. Table 5 shows the positive correlation between MELD score and $\mathrm{pNH}_{3}$ as well as a negative correlation between PSE test score and MELD score which also reached statistical significance. No significant correlation between critical flicker frequency, PSE test score, MELD score and $\mathrm{pNH}_{3}$ were found.

Specificity of surrogate markers for hepatic encephalopathy

The effect of co-morbidities on surrogate markers was assessed by their correlation with biochemical parameters of liver function. 
Table 3 Paired analysis for surrogate parameters of hepatic encephalopathy in nine individual patients who were assessed before and after liver transplantation. ( $\mathrm{pNH}_{3}$ was only available for three patients).
Differences between groups were tested for statistical significance by Student's $t$-test or the Wilcoxon test for paired samples

\begin{tabular}{|c|c|c|c|c|c|}
\hline & & $\begin{array}{l}\text { Patients with } \\
\text { liver cirrhosis median } \\
(95 \% \mathrm{CI})\end{array}$ & $\begin{array}{l}\text { Patients after } \\
\text { liver transplantation } \\
\text { median }(95 \% \mathrm{CI})\end{array}$ & $\begin{array}{l}\text { Mean difference } \\
\text { before and after } \\
\text { LT }(95 \% \mathrm{CI})\end{array}$ & Significance \\
\hline $\mathrm{pNH}_{3} \times 10^{-5} \mathrm{mmHg}$ & & $6.0(3.3-8.1)$ & $1.6(1.3-2.1)$ & $-3.96(-1.89--6.4)$ & 0.014 \\
\hline PSE test & & $-10.0(-15.9-3.4)$ & $-10.0(-20.0-5.9)$ & $5.00(-8.2--1.9)$ & 0.006 \\
\hline Median CFF [Hz] & & $34.6(12.4-55.5)$ & $44.8(4.8-77.4)$ & $3.96(-9.3--1.33)$ & 0.123 \\
\hline \multirow[t]{3}{*}{ LATER parameters } & $\mu$ & $2.8(1.8-4.4)$ & $4.0(2.3-5.2)$ & $0.13(0.67--0.41)$ & 0.602 \\
\hline & $\sigma$ & $1.1(0.3-1.6)$ & $1.0(0.9-1.1)$ & $-0.04(0.42--0.50)$ & 0.841 \\
\hline & $\sigma_{\mathrm{E}}$ & $3.4(-4.3-10.5)$ & $4.1(-3.1-8.6)$ & $0.47(2.5--1.56)$ & 0.607 \\
\hline
\end{tabular}

Saccadic latencies are known to increase with age (Irving et al. 2006), and this was confirmed by a positive correlation with age $(r=0.457, p<0.001)$. In addition to the correlation with the other parameters of encephalopathy (PSE Test, critical flicker frequency), a significant correlation was also found between $\mu$ (median saccadic latency) and the platelet count $(r=0.319 p=0.001) . \sigma_{\mathrm{E}}$ correlated negatively with bilirubin $(r=-0.212 p=0.032)$ and negatively with INR ( $r=-0.22 p=0.02)$.

The negative effect of impaired renal function and hyponatraemia/hypokalaemia on neuropsychiatric performance is illustrated by a negative correlation between the PSE Test score and urea $(r=-0.29 p=0.005)$ and a positive correlation with sodium and potassium $(r=0.361 p=0.005$, $r=0.213 p=0.05$ ). PSE test score also correlated with haemoglobin, platelets INR and albumin. Renal function

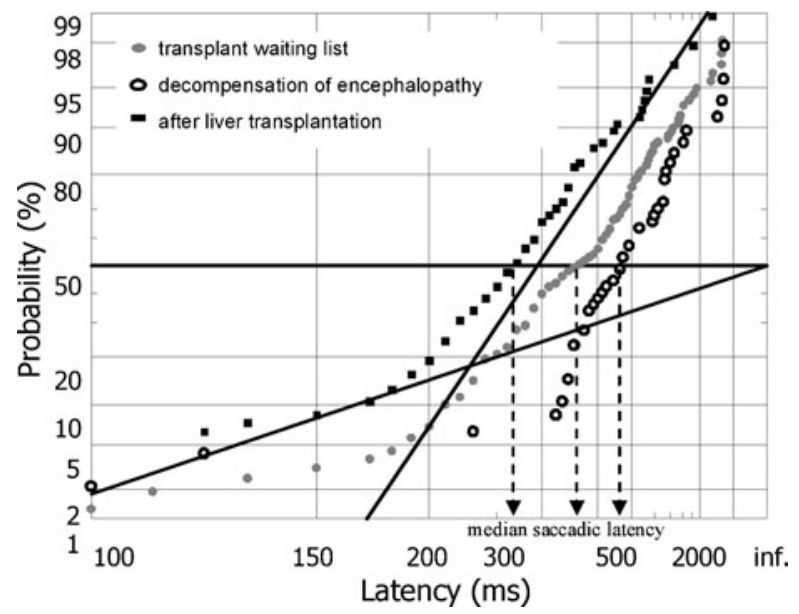

Fig. 4 Reciprobit plots summarizing the saccadic data from the patient presented in Table 1. The intercept of the $50^{\text {th }}$ percentile and the best-fit line indicates median saccadic latency (projection to the abscissa indicated by the dashed arrows). The slope of the line corresponds to the LATER parameter $\sigma$. Note that improvement of mean saccadic latency after transplantation is associated with a shift of the regression line, implying an increase in the LATER parameter $\sigma \mathrm{E}$ and electrolyte imbalances appear to have only a minor effect on saccadic latency and critical flicker frequency. Finally, $\mathrm{pNH}_{3}$ correlated significantly with age, leucocyte count, haemoglobin, platelets and AST.

Aetiology of liver disease and hepatic encephalopathy

To test if patients with alcoholic liver disease presented with more severe impairment all cirrhotic patients were grouped according to the underlying cause of their liver disease. Psychometric test performance, median saccadic latency $(\mu)$, CFF and MELD score were slightly worse in the alcoholic liver disease group, when compared with patients with other causes of liver cirrhosis, but these differences did not reach statistical significance $(p>0.05)$.

\section{Discussion}

Hepatic encephalopathy is a common complication of chronic liver disease and affects prognosis (Bustamante et al. 1999) and quality of life (Groeneweg et al. 1998; Tarter et al. 1991; Wein et al. 2004). Clinical grading of its severity, usually by the West Haven criteria, is subjective and has led to its exclusion from organ allocation criteria. There is therefore an urgent need for quantitative and objective bed-side tools for the assessment of neuropsychiatric impairment in patients with cirrhosis.

We found that cirrhotic patients have prolonged saccadic latencies when compared with transplanted patients. Analysis also showed that latencies correlate positively with the MELD score and negatively with psychometric testing results, validating latency as an objective indicator of cognitive impairment in liver disease. Median latencies correlated negatively with critical flicker frequency, but in contrast to a previous study, no correlation between CCF and psychometric test performance was found (Kircheis et al. 2002). The CCF was originally developed as a tool for the assessment of 
Table 4 Biochemical parameters and surrogate markers of hepatic encephalopathy during follow up of a single representative patient who initially presented with cholestatic decompensation of alcoholic liver cirrhosis three years after initial diagnosis. At the time of presentation, portal hypertension with hepato-splenomegaly and oesophageal varices, as well as grade II hepatic encephalopathy were diagnosed. During follow up after three months hepatic encephalopathy had deteriorated despite apparent improvement in cholestasis. In the 5 month, this patient received a liver transplant and was then reassessed for hepatic encephalopathy at day 26 after surgery

\begin{tabular}{llll}
\hline & $\begin{array}{l}\text { Month 1 presentation with } \\
\text { decompensated cirrhosis }\end{array}$ & $\begin{array}{l}\text { Month 3 decompensation of hepatic } \\
\text { encephalopathy }\end{array}$ & $\begin{array}{l}\text { Month } 626 \text { days after liver } \\
\text { transplantation }\end{array}$ \\
\hline $\begin{array}{l}\text { Creatinine } \\
(0.67-1.17 \mathrm{mg} / \mathrm{dl})\end{array}$ & $0.64 \mathrm{mg} / \mathrm{dl}$ & $0.9 \mathrm{mg} / \mathrm{dl}$ & $1.1 \mathrm{mg} / \mathrm{dl}$ \\
$\begin{array}{c}\text { Prothrombin time } \\
(70-130 \%)\end{array}$ & $49 \%$ & $36 \%$ & $90 \%$ \\
$\begin{array}{c}\text { C-reactive protein } \\
(0-0.7 \mathrm{mg} / \mathrm{dl})\end{array}$ & $2.49 \mathrm{mg} / \mathrm{dl}$ & $3.55 \mathrm{mg} / \mathrm{dl}$ & $1.1 \mathrm{mg} / \mathrm{dl}$ \\
$\begin{array}{c}\text { Bilirubin } \\
(0-1.28 \mathrm{mg} / \mathrm{dl})\end{array}$ & $36.26 \mathrm{mg} / \mathrm{dl}$ & $24.07 \mathrm{mg} / \mathrm{dl}$ & $1.08 \mathrm{mg} / \mathrm{dl}$ \\
$\begin{array}{c}\text { MELD score } \\
\text { Median critical flicker } \\
\text { frequency }\end{array}$ & 18.05 & 21.09 & 8.07 \\
$\begin{array}{c}\text { Psychometric test } \\
\text { performance }\end{array}$ & $33.9 \mathrm{~Hz}$ & $45.75 \mathrm{~Hz}$ & $41.65 \mathrm{~Hz}$ \\
\begin{tabular}{l} 
Median saccadic latency \\
\hline
\end{tabular} & $352.5 \mathrm{~ms}$ & -17 & -4 \\
\hline
\end{tabular}

Table 5 Correlations between surrogate markers of hepatic encephalopathy

\begin{tabular}{|c|c|c|c|c|c|c|c|c|c|}
\hline & & & \multirow[t]{2}{*}{$\mathrm{pNH}_{3}$} & \multirow[t]{2}{*}{ MELD score } & \multirow{2}{*}{$\begin{array}{l}\text { Critical } \\
\text { flicker } \\
\text { frequency }\end{array}$} & \multirow[t]{2}{*}{ PSE Test performance } & \multicolumn{3}{|c|}{ LATER parameters } \\
\hline & & & & & & & $\mu$ & $\sigma$ & $\sigma_{\mathrm{E}}^{\mathrm{a}}$ \\
\hline \multirow[t]{3}{*}{$\mathrm{pNH}_{3}$} & & $\mathrm{R}$ & & 0.335 & -0.169 & -0.336 & -0.224 & -0.047 & -0.279 \\
\hline & & Sig. & & 0.005 & 0.175 & 0.008 & 0.064 & 0.704 & 0.020 \\
\hline & & $\mathrm{N}$ & & 69 & 66 & 62 & 69 & 69 & 69 \\
\hline \multirow[t]{3}{*}{ MELD score } & & $\mathrm{R}$ & 0.335 & & -0.037 & -0.485 & -0.272 & 0.017 & -0.165 \\
\hline & & Sig. & 0.005 & & 0.721 & $<0.001$ & 0.006 & 0.869 & 0.100 \\
\hline & & $\mathrm{N}$ & 69 & & 98 & 90 & 101 & 101 & 101 \\
\hline \multirow[t]{3}{*}{ Critical flicker frequency } & & $\mathrm{R}$ & -0.169 & -0.037 & & 0.107 & 0.318 & 0.046 & 0.117 \\
\hline & & Sig. & 0.175 & 0.721 & & 0.319 & 0.001 & 0.653 & 0.250 \\
\hline & & $\mathrm{N}$ & 66 & 98 & & 89 & 99 & 99 & 99 \\
\hline \multirow[t]{3}{*}{ PSE Test performance } & & $\mathrm{R}$ & -0.336 & -0.485 & 0.107 & & 0.495 & -0.025 & 0.058 \\
\hline & & Sig. & 0.008 & $<0.001$ & 0.319 & & $<0.001$ & 0.810 & 0.583 \\
\hline & & $\mathrm{N}$ & 62 & 90 & 89 & & 92 & 92 & 92 \\
\hline \multirow[t]{9}{*}{ LATER parameters } & $\mu$ & $\mathrm{R}$ & -0.224 & -0.272 & 0.318 & 0.495 & & 0.051 & -0.104 \\
\hline & & Sig. & 0.064 & 0.006 & 0.001 & $<0.001$ & & 0.556 & 0.234 \\
\hline & & $\mathrm{N}$ & 69 & 101 & 99 & 92 & & 133 & 133 \\
\hline & $\sigma$ & $\mathrm{R}$ & -0.047 & 0.017 & 0.046 & -0.025 & 0.051 & & 0.168 \\
\hline & & Sig. & 0.704 & 0.869 & 0.653 & 0.810 & 0.556 & & 0.054 \\
\hline & & $\mathrm{N}$ & 69 & 101 & 99 & 92 & 133 & & 133 \\
\hline & $\sigma_{\mathrm{E}}^{\mathrm{a}}$ & $\mathrm{R}$ & -0.279 & -0.16 & 0.117 & 0.058 & -0.104 & 0.168 & \\
\hline & & Sig. & 0.020 & 0.10 & 0.250 & 0.583 & 0.234 & 0.054 & \\
\hline & & $\mathrm{N}$ & 69 & 101 & 99 & 92 & 133 & 133 & \\
\hline
\end{tabular}

${ }^{\mathrm{a}}$ Correlation of $\sigma \mathrm{E}$ and other surrogate parameters was tested by Spearman rank correlation analysis. For all other parameters, Pearson correlation analysis was carried out, since were the normally distributed (Kolmogorov-Smirnov test). Statistically significant correlations $(p<0.05)$ are highlighted in bold 
minimal or mild hepatic encephalopathy. Our study included patients with more advanced neuro-psychiatric impairment and differences in the study population may explain this discrepancy. Unlike CCF assessment, measuring saccadic latencies requires little patient comprehension or compliance as these movements are triggered sub-consciously. They can therefore be assessed even in those patients who have severe cognitive impairment (Roos et al. 2008); saccadometry may be particularly helpful at the more severe end of the clinical spectrum.

In this study, we normally made 200 single measurements to calculate median saccadic latency, taking around 10 min to collect: approximately the same time required to obtain 8 single critical flicker frequencies (Kircheis et al. 2002). We also found that the distribution of repeated CCF measurements in the same patient is not Gaussian. To minimize the effects of potential outliers, the median of repeated measurements was calculated for each patient. With increasing severity of hepatic encephalopathy, the task of recognizing the flickering light in the CCF test becomes more difficult and the results increasingly inconsistent.

The negative correlation between psychometric test performance and urea and the positive correlation with sodium and potassium suggest a direct effect of impaired renal function or hyponatraemia on brain function. No such association was seen between mild to moderate electrolyte imbalances or mildly impaired renal function and saccadic latency or critical flicker frequency, suggesting their specificity for HE.

Recent studies have shown that inflammation is a key factor in the pathogenesis of hepatic encephalopathy (Shawcross et al. 2004). However, no correlation between C-reactive protein and any surrogate parameters of hepatic encephalopathy including saccadic latency parameters (LATER parameters) was found. Because patients with infectious complications or severe inflammation were excluded from the study, a different design would be required to test if saccadic latencies are a sensitive parameter for spetic encephalopathy and to assess the interaction between inflammation and ammonia in the pathogenesis of hepatic encephalopathy.

Whereas saccadic latencies increase with age (Irving et al. 2006) our study showed no relationship between age and $\mathrm{CCF}$, suggesting that saccadic latency is more sensitive for subtle cognitive impairment, as in aging. To determine if latency is an independent prognostic parameter in cirrhosisas suggested by its correlation with the MELD score-will require further prospective studies. Although hepatic encephalopathy is a common complication of cirrhosis, it is not known if the prognostic value is due to the fact that hepatic encephalopathy itself is also a surrogate marker of liver function (Bustamante et al. 1999). Quantitative assessment of neurological impairment in patients with cirrhosis CFF or saccadic latency recordings offers a way to study the impact of encephalopathy on patient outcome.

Rather than simply relying on correlations between latency and other markers of liver function we recorded individual improvement in latencies after patients were transplanted. As expected, we found improvements in their individual median saccadic latencies after surgery, but this difference did not reach statistical significance $(p>0.05)$. Psychometric test performance improved significantly after liver transplantation, validating our patient cohort as a model system for hepatic encephalopathy. In two patients, median saccadic latencies increased after liver transplantation and this may reflect irreversible and progressive neurological deterioration (Mechtcheriakov et al. 2004) or result from immunosuppressive therapy (Lewis and Howdle 2003; Walker and Brochstein 1988; Wijdicks 2001). This notion is supported by the significant difference seen between the transplanted patient group and the age and sex-matched healthy control subjects.

We also noted a positive correlation between the prevalence of early saccades and $\mathrm{pNH}_{3}$, which suggests a selective neurotoxic effect of ammonia within the brain, since early saccades are believed to represent saccades initiated sub-cortically that escape normal tonic inhibition from the cortex, whereas the majority of saccades are controlled by neural 'decision units' in the cortex (Schiller and Tehovnik 2001). Assessment of saccadic latencies and evaluation of the data with the LATER model therefore offers a practical tool to study higher cerebral neurophysiology in liver cirrhosis.

In conclusion, our study suggests that median saccadic latency is an objective and specific marker of hepatic encephalopathy and can be reliably determined in patients even at advanced stages of neurological impairment. Saccadic latencies are unaffected by kidney function, plasma sodium concentration or inflammatory markers, making them an excellent tool with which to assess hepatic encephalopathy in clinical practice.

Acknowledgements The authors are indebted to Nadja Baumgartner for excellent technical support.

F.K. was supported by a grant (i-med Forschungsstipendium) from the Medical University of Innsbruck to complete this work. Publication of this work was supported by the Verein zur Förderung der Forschung in Gastreonterologie und Hepatologie an der Medizinischen Universität Innsbruck.

Competing interests FK, JR, MS, IWG, VW and HZ have no conflict of interest. RHSC is an unpaid director of a company distributing the saccadometer.

Open Access This article is distributed under the terms of the Creative Commons Attribution Noncommercial License which permits any noncommercial use, distribution, and reproduction in any medium, provided the original author(s) and source are credited. 


\section{References}

Ali FR, Michell AW, Barker RA, Carpenter RH (2006) The use of quantitative oculometry in the assessment of Huntington's disease. Exp Brain Res Exp Hirnforsch 169:237-245

Antoniades CA, Altham PM, Mason SL, Barker RA, Carpenter R (2007) Saccadometry: a new tool for evaluating presymptomatic Huntington patients. NeuroReport 18:1133-1136

Bustamante J, Rimola A, Ventura PJ, Navasa M, Cirera I, Reggiardo V, Rodes J (1999) Prognostic significance of hepatic encephalopathy in patients with cirrhosis. J Hepatol 30:890-895

Butterworth RF (2002) Pathophysiology of hepatic encephalopathy: a new look at ammonia. Metab Brain Dis 17:221-227

Butterworth RF, Giguere JF, Michaud J, Lavoie J, Layrargues GP (1987) Ammonia: key factor in the pathogenesis of hepatic encephalopathy. Neurochem Pathol 6:1-12

Cairney S, Maruff P, Burns CB, Currie J, Currie BJ (2005) Neurological and cognitive recovery following abstinence from petrol sniffing. Neuropsychopharmacology 30:1019-1027

Carpenter R (1994) SPIC: a PC-based system for rapid measurement of saccadic responses. J Physiol (Proc) 480:4P

Carpenter RH, Williams ML (1995) Neural computation of log likelihood in control of saccadic eye movements. Nature 377:59-62

Carpenter RH, Descamps MJ, Morley CH, Leary TS, Jones JG (2002) The effect of low dose sevoflurane on saccadic eye movement latency. Anaesthesia 57:855-859

de Visser SJ, van der Post JP, de Waal PP, Cornet F, Cohen AF, van Gerven JM (2003) Biomarkers for the effects of benzodiazepines in healthy volunteers. Br J Clin Pharmacol 55:39-50

Ferenci P, Lockwood A, Mullen K, Tarter R, Weissenborn K, Blei AT (2002) Hepatic encephalopathy - definition, nomenclature, diagnosis, and quantification: final report of the working party at the 11th World Congresses of Gastroenterology, Vienna, 1998. Hepatology 35:716-721

Foltynie T, Brayne CE, Robbins TW, Barker RA (2004) The cognitive ability of an incident cohort of Parkinson's patients in the UK. The CamPaIGN study. Brain 127:550-560

Groeneweg M, Quero JC, De Bruijn I, Hartmann IJ, Essink-bot ML, Hop WC, Schalm SW (1998) Subclinical hepatic encephalopathy impairs daily functioning. Hepatology 28:4549

Irving EL, Steinbach MJ, Lillakas L, Babu RJ, Hutchings N (2006) Horizontal saccade dynamics across the human life span. Invest Ophthalmol Vis Sci 47:2478-2484

Jalan R, Hayes PC (1997) Hepatic encephalopathy and ascites. Lancet 350:1309-1315

Karoumi B, Ventre-Dominey J, Vighetto A, Dalery J, d'Amato T (1998) Saccadic eye movements in schizophrenic patients. Psychiatry Res 77:9-19

Khan O, Taylor SJ, Jones JG, Swart M, Hanes DP, Carpenter RH (1999) Effects of low-dose isoflurane on saccadic eye movement generation. Anaesthesia 54:142-145

Kircheis G, Wettstein M, Timmermann L, Schnitzler A, Haussinger D (2002) Critical flicker frequency for quantification of low-grade hepatic encephalopathy. Hepatology 35:357-366

Kircheis G, Fleig WE, Gortelmeyer R, Grafe S, Haussinger D (2007) Assessment of low-grade hepatic encephalopathy: a critical analysis. J Hepatol 47:642-650

Kolmogorov A (1941) Confidence limits for an unknown distribution function. Ann Math Stat 23:525-540

Kramer L (2004) Acute liver failure. Wien Klin Wochenschr 116:6781

Kramer L, Tribl B, Gendo A, Zauner C, Schneider B, Ferenci P, Madl C (2000) Partial pressure of ammonia versus ammonia in hepatic encephalopathy. Hepatology 31:30-34
Lewis MB, Howdle PD (2003) Neurologic complications of liver transplantation in adults. Neurology 61:1174-1178

Manning RT (1964) A Nomogram for Estimation of Pnh3. J Lab Clin Med 63:297-298

Mechtcheriakov S, Graziadei IW, Mattedi M, Bodner T, Kugener A, Hinterhuber HH, Marksteiner J, Vogel W (2004) Incomplete improvement of visuo-motor deficits in patients with minimal hepatic encephalopathy after liver transplantation. Liver Transplant 10:77-83

Mechtcheriakov S, Graziadei IW, Kugener A, Wiedemann J, Galbavy C, Hinterhuber H, Marksteiner J, Vogel W (2005) Multidimensional assessment of neuro-psychiatric symptoms in patients with low-grade hepatic encephalopathy: a clinical rating scale. World J Gastroenterol 11:5893-5898

Michell AW, Xu Z, Fritz D, Lewis SJ, Foltynie T, Williams-Gray CH, Robbins TW, Carpenter RH, Barker RA (2006) Saccadic latency distributions in Parkinson's disease and the effects of L-dopa. Exp Brain Res Exp Hirnforsch 174:7-18

Montagnese S, Gordon HM, Jackson C, Smith J, Tognella P, Jethwa N, Sherratt RM, Morgan MY (2005) Disruption of smooth pursuit eye movements in cirrhosis: relationship to hepatic encephalopathy and its treatment. Hepatology 42:772-781

Moore KA, Mc LJR, Burrows GD (2000) Quality of life and cognitive function of liver transplant patients: a prospective study. Liver Transplant 6:633-642

Nouraei SA, De Pennington N, Jones JG, Carpenter RH (2003) Dose-related effect of sevoflurane sedation on higher control of eye movements and decision making. Br J Anaesth 91:175183

Ober J, Przedpelska-Ober E, Gryncewicz W, Dylak J, Carpenter R, Ober J (2003) Hand-held system for ambulatory measurement of saccadic durations of neurological patients. In: Gajda J (ed) Modelling and Measurement in Medicine. Komitet Biocybernityki i Inzyneierii Biomedycznej PAN, Warsaw, pp $187-198$

Pearson BC, Armitage KR, Horner CW, Carpenter RH (2007) Saccadometry: the possible application of latency distribution measurement for monitoring concussion. $\mathrm{Br} \mathrm{J}$ Sports Med 41:610-612

Reddi BA, Carpenter RH (2000) The influence of urgency on decision time. Nat Neurosci 3:827-830

Reddi BA, Asrress KN, Carpenter RH (2003) Accuracy, information, and response time in a saccadic decision task. J Neurophysiol 90:3538-3546

Romero-Gomez M, Cordoba J, Jover R, del Olmo JA, Ramirez M, Rey R, de Madaria E, Montoliu C, Nunez D, Flavia M et al (2007) Value of the critical flicker frequency in patients with minimal hepatic encephalopathy. Hepatology 45:879885

Roos JCP, Lachmann R, Cox TM, Carpenter RHS (2006) Saccadometry for estimating cerebral damage in storage diseases. Acta Paediatr 95:139-144

Roos JC, Calandrini DM, Carpenter RH (2008) A single mechanism for the timing of spontaneous and evoked saccades. Exp Brain Res 187(2):283-293

Rovira A, Cordoba J, Raguer N, Alonso J (2002) Magnetic resonance imaging measurement of brain edema in patients with liver disease: resolution after transplantation. Curr Opin Neurol 15:731-737

Schiller PH, Tehovnik EJ (2001) Look and see: how the brain moves your eyes about. Prog Brain Res 134:127-142

Schomerus H, Hamster W (1998) Neuropsychological aspects of portal-systemic encephalopathy. Metab Brain Dis 13:361-377

Schomerus H, Weissenborn K, Hamster W, Rückert N, Hecker H (1999) PSE-Test-Manual. In Swet Test Services (Frankfurt)

Shawcross DL, Davies NA, Williams R, Jalan R (2004) Systemic inflammatory response exacerbates the neuropsychological 
effects of induced hyperammonemia in cirrhosis. J Hepatol 40:247-254

Tarter RE, Switala J, Arria A, Van Thiel DH (1991) Impact of liver disease on daily living in transplantation candidates. J Clin Epidemiol 44:1079-1083

Temel Y, Visser-Vandewalle V, Carpenter RH (2009) Saccadometry: a novel clinical tool for quantification of the motor effects of subthalamic nucleus stimulation in Parkinson's disease. Exp Neurol 216:481-489
Walker RW, Brochstein JA (1988) Neurologic complications of immunosuppressive agents. Neurol Clin 6:261-278

Wein C, Koch H, Popp B, Oehler G, Schauder P (2004) Minimal hepatic encephalopathy impairs fitness to drive. Hepatology 39:739-745

Weissenborn K, Ennen JC, Schomerus H, Ruckert N, Hecker H (2001) Neuropsychological characterization of hepatic encephalopathy. J Hepatol 34:768-773

Wijdicks EF (2001) Neurotoxicity of immunosuppressive drugs. Liver Transplant 7:937-942 